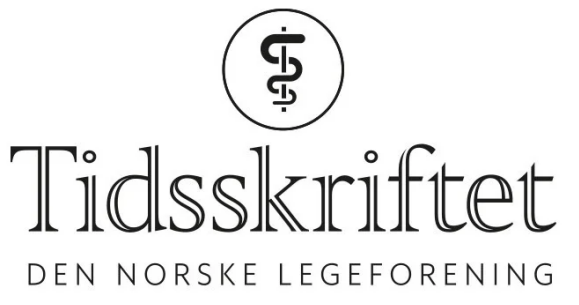

\title{
Kjuagutten som helst ville spille saksofon
}

INTERVJU

\section{JANNIKE REYMERT}

jannike.reymert@gmail.com

$\emptyset y s t e i n$ Søbstad sier han er en jazzmusiker som har rehabilitert seg til lege. Sannheten er at han har spilt på mange strenger gjennom livet. 


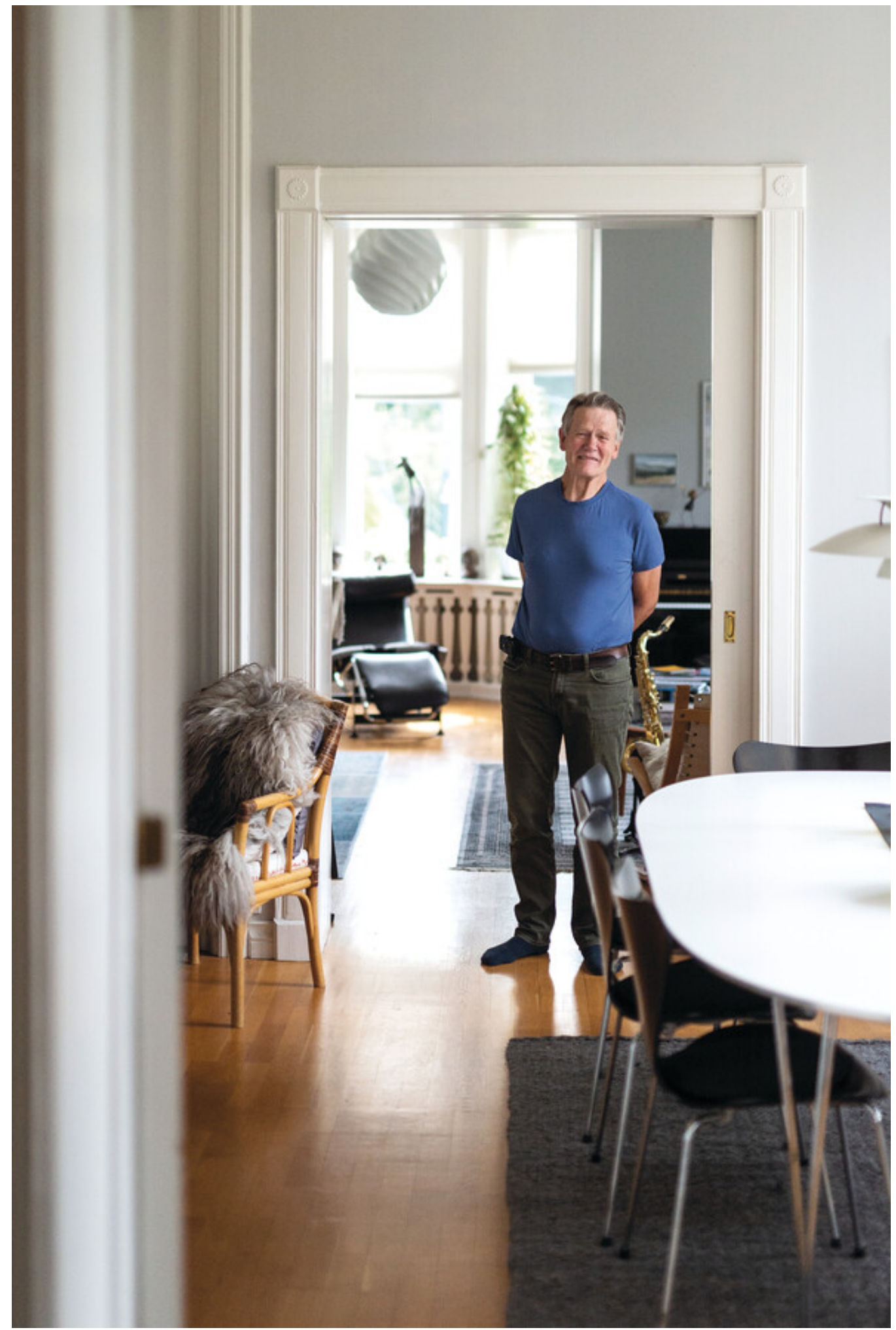

Foto: Magne Sandnes

Musikkarrieren ble mer enn en hobby da han fikk blåse trompet under avtjening av militærtjenesten. Etterpå gikk turen til Sverige der han livnærte seg som freelancemusiker i flere år.

- Jeg ville helst spille jazz, men i 1970-årene var jazzen død i Norden, særlig i Sverige. Det var populærmusikk som gjaldt, og jeg fikk spille med kjente, populære artister som blant annet Lill Lindfors, Cornelis Vreeswijk og Lill-Babs.

Så ville han reise til USA for å videreutvikle musikklidenskapen.

- Men der var det ikke takhøyde for folk med radikale ideer i hodet. Det ble ingen musikkutdanning på meg, og jeg fortsatte som en halvstudert fløytist i Skandinavia.

\section{Det vanskelige valget}


Øystein er vokst opp på Horsøy, en litt isolert øy utenfor Askøy. Her lå en av Norges største sildolje- og sildemelfabrikker, der hans far var sjef.

\section{Øystein Søbstad}

Født 12.10.1945

Cand.med. 1981

Spesialist i allmennmedisin 1989

Allmennlege på Askøy 1983-94

Helsesjef i Løvstakken bydel i Bergen 1994-98

Smittevernoverlege i Bergen kommune 1998-2015

Har hatt mange spilleoppdrag i Bergen fra 15-årsalderen

Frilansmusiker i flere land 1966-72

- Alt er historie nå, øya er rasert av industriutbygging. Barndommen min er borte. Det er trist.

Moren var pianist og bidro til at han lærte noter før han lærte bokstaver. Faren var ingeniørutdannet og betonte viktigheten av en «ordentlig» utdanning.

- Det satt dypt i meg, og etter noen år lot jeg meg overtale til å la musikken bli en fritidssyssel. Jeg luktet litt på psykologi, men merket at kroppen og særlig fysiologien fenget mer enn å grave i sjelen.

- Angrer du på at du valgte legelivet?

- Jeg er ikke en som angrer. Jeg har jo av og til spurt meg selv hvordan livet hadde vært hvis jeg hadde blitt profesjonell musiker, men det er heldigvis mye som er spennende i medisinen også. Jeg så tidlig at jeg ville bli allmennlege. I det faget var det mange hyggelige folk som var genuint opptatt av å hjelpe pasientene. Dessuten passer allmennmedisinen for oss som har praktisk erfaring. Det har jeg i rikt monn fra jobber i industrien, byggebransjen og på havna fra den tiden jeg måtte tenke allsidig for å ha noe å leve av. 


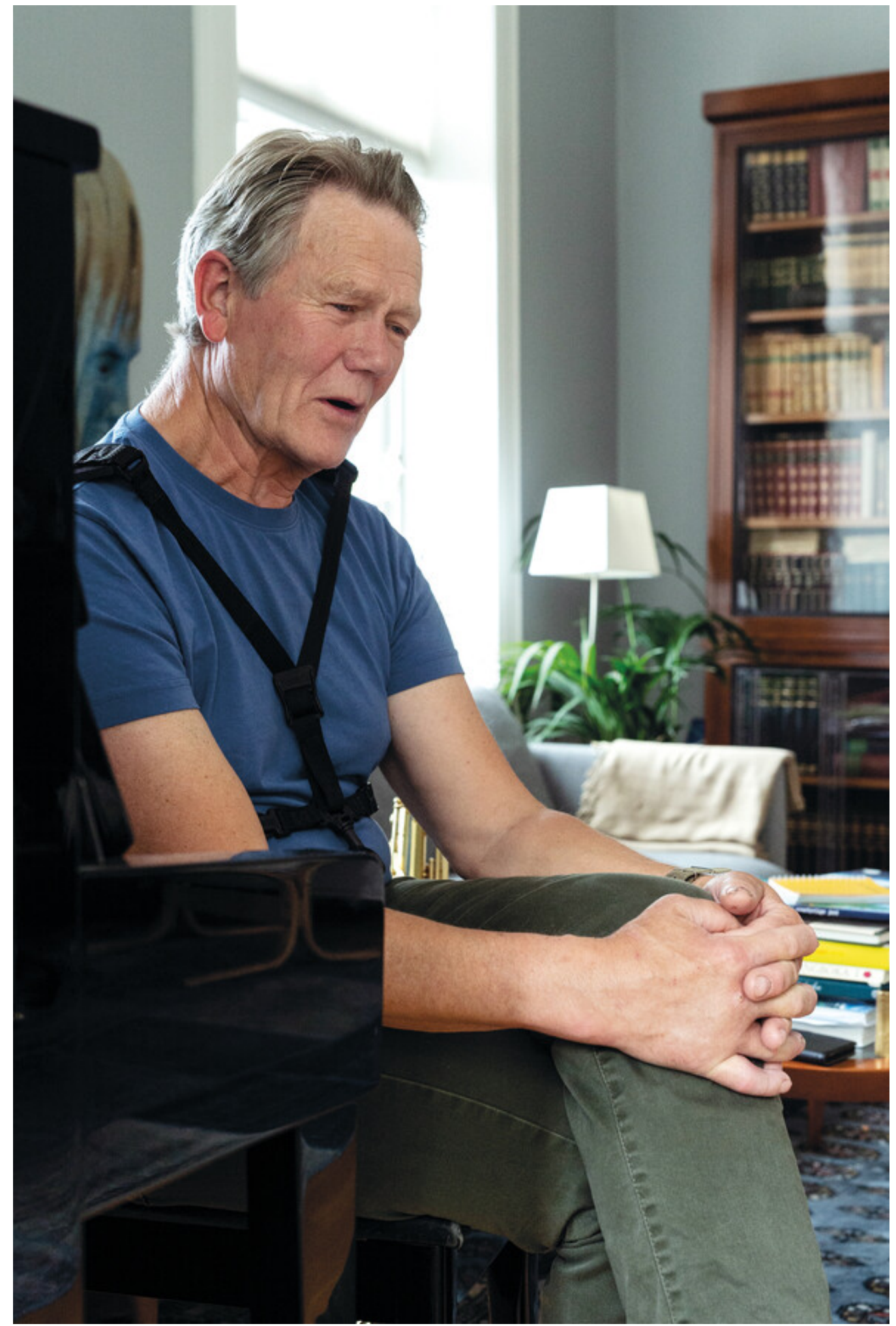

Foto: Magne Sandnes

Allmennmedisinen dekket ikke hele hans interessefelt, han trengte perspektivet som samfunnsmedisinen gav.

- Jeg ville se medisinen på et kommune- og fylkesnivå. Også her ble jeg tiltrukket av det gode miljøet med mange kolleger med stor kunnskap.

Han fikk jobb som bydelsoverlege i Bergens "grå bydel», Løvstakken, en bydel som nå er historie. Området ble også kalt Blodbyen, fordi området var preget av mye sosial uro og slåssing. Solheimsviken, grundig omtalt i Gunnar Staalesens kriminalromaner, ligger her. 
- Det han skriver om denne delen av byen, er svært beskrivende. I en av bøkene hans er jeg omtalt som «still going strong»! Jeg skal forresten opptre sammen med ham neste uke i anledning jazzklubben Swing'n'Sweets 25-årsjubileum, forteller han mens vi deler felles glede over forfatterens erkebergenske bøker.

\section{Smittevernoverlegen}

I 1998 ble Øystein Søbstad innstendig oppfordret til å søke den nyopprettede stillingen som smittevernoverlege i Bergen.

- Jeg ble veldig glad for å bli spurt. Dessverre var det ingen opplæring, og jeg måtte selv finne ut hva jeg skulle gjøre. Den første tiden gikk jeg hjem etter endt arbeidsdag og spurte meg selv: «Har jeg gjort noe i dag?».

I slutten av 1990-årene var det rundt 300 hepatitt-A-smittede blant rusmisbrukerne i byen. Det medførte en lang periode med smitteoppsporing og etter hvert vaksinering av registrerte rusbrukere.

«Vi bør og skal samarbeide med media, de er den beste kanalen for å nå ut til publikum»

- Vi etablerte et tett samarbeid med Mattilsynet. Veterinærene der hadde mye kunnskap som vi kunne dra nytte av. Vi fikk også alltid gode råd hos Folkehelsa i Oslo. Da epidemien var på sitt verste, så vi hvor viktig det var å ha en god smittevernplan. Bergen hadde ikke hatt det før smittevernloven kom i 1995.

Med en liten latter forteller han at også her ble arbeidet gjort uten opplæring.

- Jeg måtte sy sammen planen etter eget hode og kombinere det med det jeg leste meg til underveis.

\section{Giardia lamblia}

Det gode samarbeidet med Mattilsynet kom til sin rett da Bergen kommune høsten 2004 fikk et stort utbrudd av Giardia lamblia. Det var 1400 registrerte smittede, men det reelle tallet på smittede var nok 5 ooo-6 ooo.

- Det tok ikke lang tid før laboratoriet på Haukeland ble sprengt. Vi måtte stille diagnosen på grunnlag av kliniske funn. $10 \%$ responderte ikke på metronidazol (Flagyl), og $10 \%$ av dem fikk kronisk utmattelsessyndrom, altså 50-70 mennesker. Langt flere fikk irritabel tarm-syndrom. 


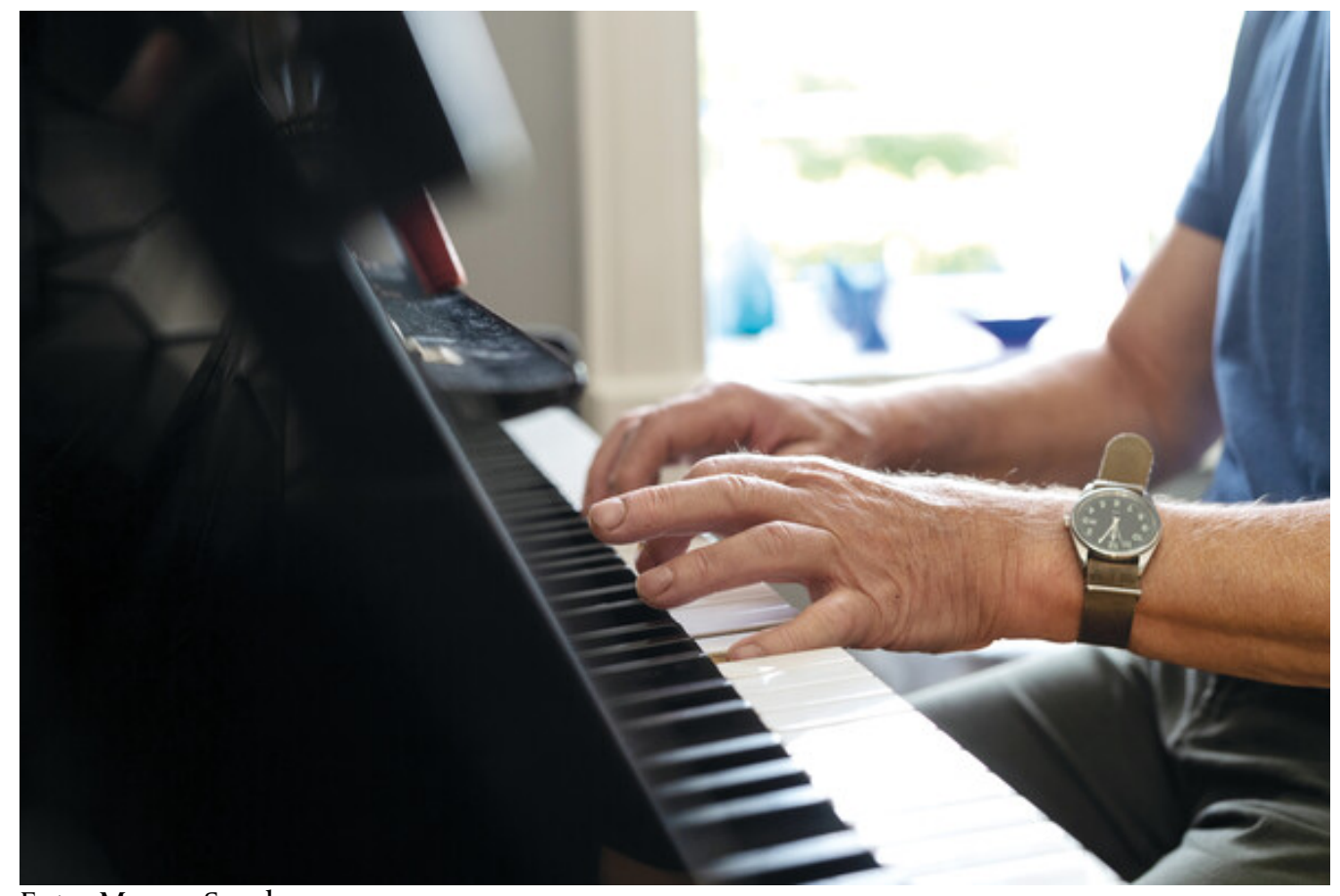

Foto: Magne Sandnes

Det han i ettertid synes de mestret best, var kontakten med media.

- Mange kolleger skyr media, men jeg tenker annerledes. Vi bør og skal samarbeide med dem, de er den beste kanalen for å nå ut til publikum. Journalistene var moderate i

begynnelsen, men så tok de av silkehanskene og satte oss til veggs for manglende framgang i oppsporing av smittekilden. Det var ubehagelig for oss som jobbet intenst for å finne smittekilden, uten hell, men såpass må man tåle - selv om vi blant annet hadde samlet inn $100 \mathrm{~kg}$ hundeskitt for å teste om smitten kom derfra.

Han fortsetter monologen:

- Det dummeste du gjør, er å avvise pressen. Da graver de mer, uten at du aner hvor det ender. Jeg tok erfaringen fra denne hendelsen med inn i smittevernplanen, der jeg betonte viktigheten av å la all informasjon til media gå via en informasjonsleder. For å gi publikum et troverdig inntrykk er det uhyre viktig at alle medarbeiderne er samkjørte, solidariske og støtter oppunder det informasjonslederen fronter utad.

- Hva lærte dere av denne hendelsen?

- Vi lærte at lærebøkene ikke alltid stemmer med virkeligheten. Videre var samarbeidet med Haukeland ble avgjørende for håndteringen av epidemien. All ros til dem som bidro sterkt i diagnostikken. De jobbet nærmest døgnet rundt en periode for å ta unna tilsendte prøver. Vi lærte også hvor viktig det er å føre nøyaktig loggbok og epidemikurve for å klare å se når epidemien roer seg. I etterkant så vi at epidemien faktisk var over da den ble meldt.

\section{Kjuagutten}

Etter Giardia-utbruddet ble han tildelt Bergen presseforenings Kjuagutt-statuett.

En kjuagutt er benevnelsen på en bergensk unggutt eller gategutt. De har glimt i øyet, er freidige og kjappe i replikken. Dessuten har de hjertet på rett sted og sterk rettferdighetssans. Språkrådet sier at det korrekte er å skrive tjuagutt, for etymologisk har ordet med tjuv å gjøre. I Bergen blir denne ekspertuttalelsen fnysende avvist med krystallklar argumentasjon: «Vi lar ikke østlendinger avgjøre slikt!»

Øystein Søbstad hever seg over denne debatten og forteller:

- Jeg hadde aldri drømt om noe sånt. Jeg satte stor pris det.

\section{Det gylne håndtak}


Giardia-utbruddets smittekilde ble sporet til den kunstige innsjøen Svartediket. Innsjøen var i 1855 kilden til Norges første moderne vannverk, hvor vannet ble ledet i uthulte tømmerstokker og trykket var så høyt at vannspruten sto 40 meter til værs på torget på innvielsesfesten.

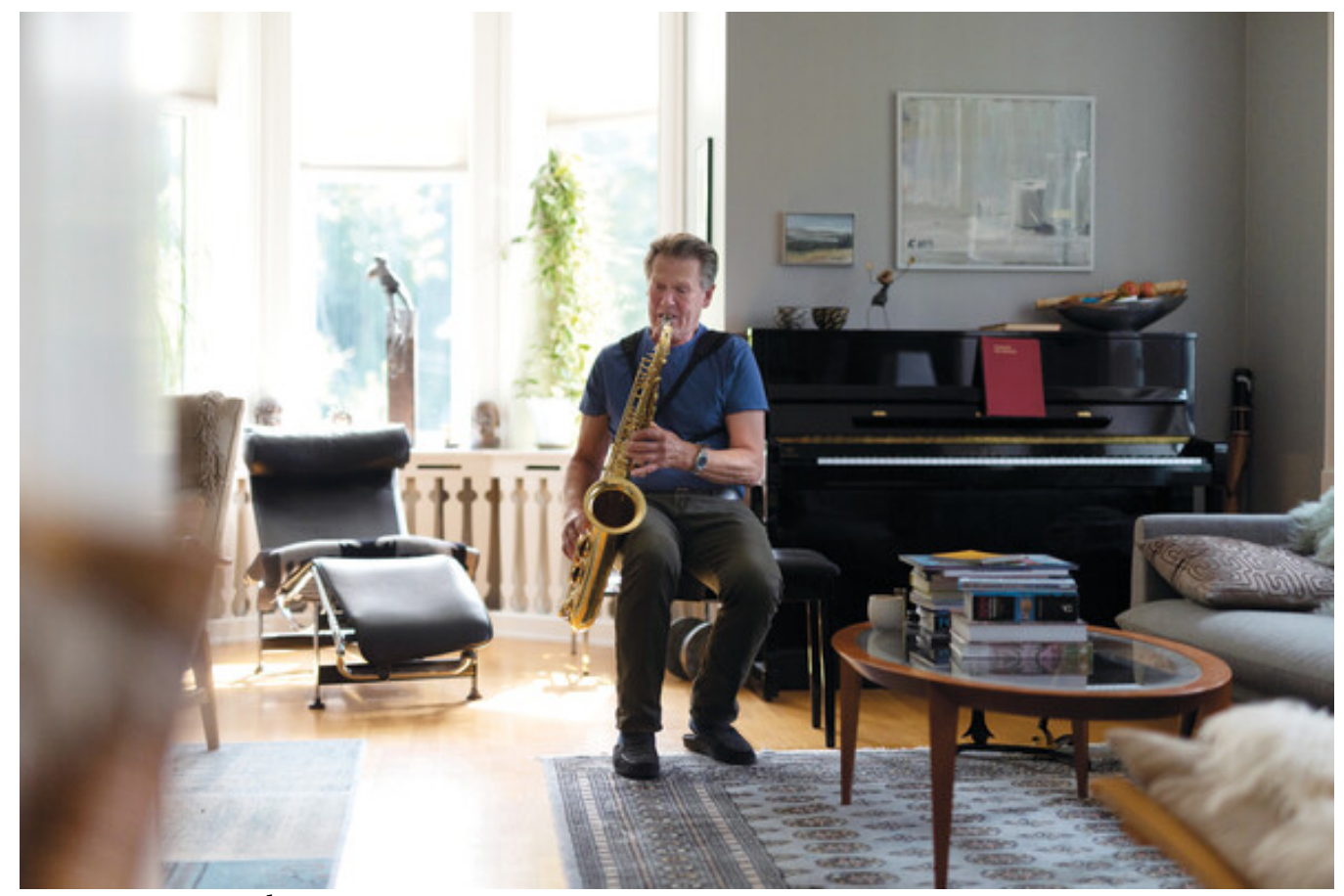

Foto: Magne Sandnes

Historisk sett har Svartediket litt dårlig rykte i byen. Under krigen hadde tyskerne kaserner i Isdalen, der vannet ligger, og de lot kloakken renne rett ut i Svartediket.

- Det er forståelig at byens innbyggere var enda mer skeptisk til tysk enn egenprodusert kloakk, kommenterer Øystein tørt.

\section{«Musikken er min form for meditasjon, scerlig den jeg improviserer»}

Giardia-utbruddet har mange likheter med koleraepidemien i London i 1854, der legen John Snow på mesterlig vis påviste at smittekilden var drikkevannet fra en brønn.

- Det er jo en fantastisk historie. Tenk hvilken skandale det var når Snow fjernet håndtaket til denne vannpumpen!

Øystein forteller at han er medlem i Det gylne håndtak, en internasjonal forening der de som er epidemiologiinteresserte og har en faglig kuriositet i bagasjen, kan bli tatt opp.

\section{Duenes verste fiende?}

Som andre større byer huser Bergen et betydelig antall tamme duer, lokalt kalt taksjabber til stor glede for både turister og byens egne innbyggere. Øystein ler hjertelig når jeg spør om hans forhold til duer.

- Jeg kom nok litt feil ut i den saken. Vi må tilbake til 2005, da det var utbrudd av fugleinfluensa. En ivrig journalist mer eller mindre la ordene i munnen min om den potensielle smittefaren duene kunne representere. Jeg foreslo å redusere bestanden, og reaksjonen uteble ikke! Jeg fikk så hatten passet. Det gikk så langt at jeg fikk drapstrusler. Til og med et medlem av Norsk huskattforening ringte meg og sa at jeg ikke fortjente lønn for arbeidet mitt og burde avskjediges. Jeg har for øvrig aldri skjønt hva dette hadde med huskattene å gjøre. 
- Jeg mener fortsatt at man må ha en viss kontroll over bestanden, også ut fra et dyreetisk synspunkt. Det kan ikke være så mange duer at de ikke får nok mat. Fugeinfluensaen er jo også en tankevekker når vi vet at småbarn løper rundt i fugleskitten, ramler over ende og tar seg for. Men nå skal det innrømmes at det aldri er påvist fugleinfluensavirus blant duer, selv om vi var redd for det. Nei, det håndterte jeg ikke særlig godt, sier han med latter i stemmen.

- Duer har en spesiell plass i folks hjerter. Det er ikke tilfeldig at vi har begrepet fredsdue, det lærte jeg grundig av denne historien.

\section{Pensjonistlivet}

Vi legger faget til side. Som pensjonist fyller Øystein Søbstad tiden med musikk.

- Medisinen var et mellomspill. Jeg tar spillejobber der jeg kommer til og har det faktisk travelt, men jeg liker å jobbe. Det går i jazz og klassisk musikk, det er det som treffer meg i hjertet. Saksofonen snakker til meg. Musikken er min form for meditasjon, særlig den jeg improviserer. Det har hjulpet meg mye.

\section{"Jeg er stort sett fornøyd med livet slik det ble. Det var smart å bli lege»}

Pensjonisttiden tilbringes ellers stadig mer i Hardanger.

- Kona mi er et levende menneske. Som nypensjonert lærer tok hun gartnerutdanning etter at vi hadde kjøpt et veiløst småbruk i Hardanger der vi dyrker grønnsaker. Her har det bodd folk i alle år, og på eiendommen ligger det en grav fra bronsealderen. Planen er å lage et kulturlandskap tilrettelagt for seilbrett, fisketurer og ikke minst epledyrking. Vi tenker også at vi kan ha musikkurs her.

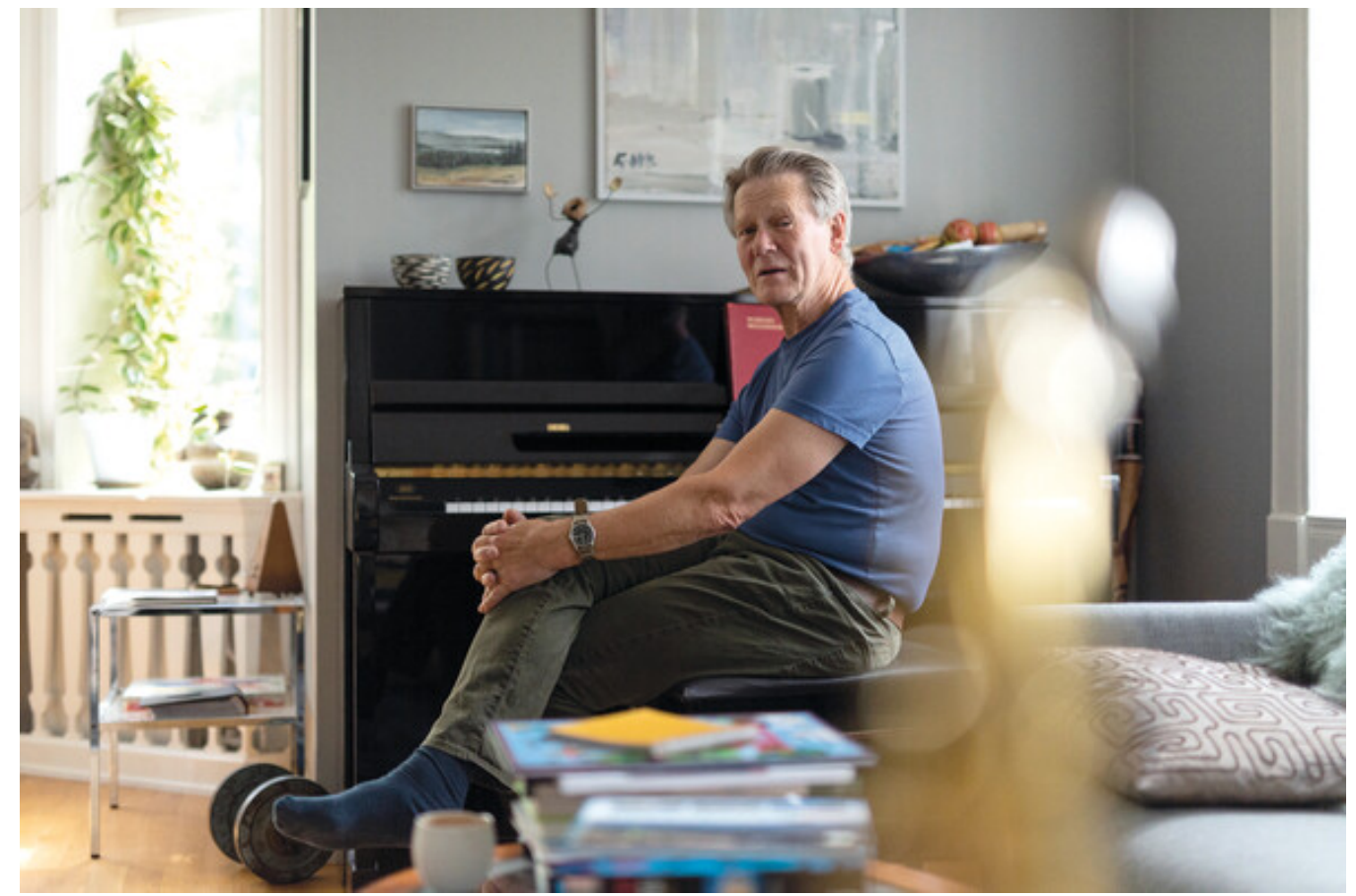

Foto: Magne Sandnes

Han blir myk i blikket:- Hardangerforden er vill og vakker, et rikt landskap. Det er så vakkert å sitte her med et glass hvitvin og se havørnen som har hentet seg en fisk, mens nisene kanskje dukker opp ute på fjorden. Her er det mink, mår og røyskatt. Vi ser ikke bort fra at vi flytter inn hit, det er jo i tiden å finne tilbake til gamle levemåter.

- Vi gjør det som er enkelt, sier han, for i neste øyeblikk å fortelle at de planlegger å plante 150 epletrær som kan gi råvarer til et eget sideri.

\section{Tilbakeblikk}


- Når du ser tilbake på yrkeslivet, hva er du mest fornøyd med?

- Jeg er stort sett fornøyd med livet slik det ble. Det var smart å bli lege. Med den utdanningen følger det så mye som gir god allmenndannelse. Nå kan jeg ta småjobber som det passer meg, og siden vi nå er blitt småbrukere, er kunnskapen om mikroflora kjekt å ha med seg fra medisinen. Når jeg ser hvor hardt livet har blitt for mange musikere, angrer jeg ikke på at jeg forlot musikkarrieren. Jeg er en god improvisator, noe jeg nyter godt av både i musikken og medisinen. Med improvisasjon følger fleksibilitet. Forutsetningen er å ha lært formspråket grundig. Jeg har alltid tenkt: Du skal ikke bare gjøre ditt, du skal gjøre det med stil, sier han og avslutter samtalen:

- Det er en fordel å være gammel, i den forstand at jeg ikke lenger lar meg sjokkere så lett som da jeg var ung. Ikke blir jeg så lett irritert heller. Før var jeg mer firkantet, nå er jeg mer åpen for ting slik de er. Som gammel er det også lettere å ha autoritet og evnen til å skjære igjennom i tide.

Til informasjon er intervjuet med Øystein Søbstad gjennomført og skrevet før koronapandemien brøt ut $i$ Norge.

Publisert: 7. september 2020. Tidsskr Nor Legeforen. DOI: 10.4045/tidsskr.20.0635

(C) Tidsskrift for Den norske legeforening 2023. Lastet ned fra tidsskriftet.no 26. april 2023. 